\title{
ANALISE DE REQUISITOS PARA UM SISTEMA DE CONTROLE DE PATRIMONIO
}

\author{
José Rafael Rocha Gomes ${ }^{1}$ \\ Arthur Scardini Domingues ${ }^{2}$ \\ Daniel Emilio de Souza ${ }^{3}$ \\ Ubiratan Roberte Cardoso Passos ${ }^{4}$
}

Resumo: O desenvolvimento de um software é composto de diversos processos e fases que, independente da metodologia utilizada trabalham para que se possa alcançar um objetivo maior: garantir a qualidade do produto final, ou seja entregar um sistema funcionando corretamente e dentro do prazo estabelecido. $O$ objetivo desse trabalho é o desenvolvimento de um modelo de dados para controle do patrimônio interno do instituto. A modelagem foi realizada aplicando técnicas de análise de sistemas, tomando como referência o setor e patrimônio do Instituto Federal do Espírito Santo - Campus Alegre (ES), local onde foram coletadas as informações. Ao final desse trabalho pode-se observar que o modelo atendeu aos requisitos levantados, mostrando-se como um poderoso aliado ao gestor no controle dos bens patrimoniais.

Palavras-chave: Informações; Metodologia; Patrimônio; Software.

\footnotetext{
${ }^{1}$ Tecnologia em Analise e Desenvolvimento de Sistemas/Instituto Federal do Espírito Santo - Campus de Alegre, Brasil. E-mail: rafael_mdr@hotmail.com.

${ }^{2}$ Tecnologia em Analise e Desenvolvimento de Sistemas/Instituto Federal do Espírito Santo - Campus de Alegre, Brasil. E-mail: arthurdomingues91@hotmail.com.

${ }^{3}$ Tecnologia em Analise e Desenvolvimento de Sistemas/Instituto Federal do Espírito Santo - Campus de Alegre, Brasil. E-mail: daniel377@hotmail.com.

${ }^{4}$ Docente Mestre/Instituto Federal do Espírito Santo - Campus de Alegre, Brasil. E-mail: upassos@gmail.com.
} 